\title{
Brasileiros na fronteira com o Paraguai
}

\author{
MARCIA ANITA SPRANDEL
}

\begin{abstract}
É preciso atravessar a tela das projeções geralmente absurdas, às vezes odiosas, atrás das quais o mal-estar ou o sofrimento se escondem tanto quanto se expressam.
\end{abstract}

(Bourdieu, 1997, p.735)

$\mathrm{E}$ SCREVER SOBRE brasileiros que vivem em território paraguaio exige um exercício constante de fuga de estereótipos e imagens midiatícas, repetidas ad nauseum. ${ }^{1}$ A construção de "realidades" pela mídia tem um poder imenso, que apenas se iguala ao das representações políticas, especialmente aquelas referentes a populações categorizados em algum momento como "problemas" ou a lugares “ditos difíceis" (Bourdieu,1997, p.11).

Um exercício de pesquisa em notícias de jornais e revistas semanais brasileiros, nos últimos vinte anos, mostra a tediosa repetição de uma mesma narrativa: os "brasiguaios" são apresentados como um grupo social formado por centenas de milhares de camponeses brasileiros (as estimativas mais razoáveis variam de trezentas a quinhentas mil pessoas), que se transferiram para a fronteira leste do Paraguai na década de 1970, expulsos pela monocultura da soja e pela construção de Itaipu, num contexto de disputas geopolíticas, e que no Paraguai (apesar de "terem levado o progresso econômico ao campo") enfrentam sérios problemas de documentação, titulação de terras e conflitos com o movimento camponês paraguaio. Essa mesma representação aparece nas audiências públicas realizadas na Assembléia Legislativa do Estado do Paraná ou no Congresso Nacional, nos inúmeros seminários realizados por instâncias de governo dos dois países para tratar do assunto e nos discursos de políticos e diplomatas.

Se invertermos o olhar e pesquisarmos em jornais e revistas paraguaios, como bem demonstra Albuquerque (2005), teremos uma outra visão, também homogeneizadora, dos brasileiros que vivem no Paraguai: empresários ricos, imperialistas, atraídos pelos baixos preços das terras e pela abolição da proibição de compra de terras por estrangeiros (promovida por Stroessner, em 1967), introdutores da monocultura da soja, responsáveis pela expansão da sola transgênica no país, expulsores de camponeses sem terra e índios e devastadores das florestas e do meio ambiente.

Tentar fugir das representações midiáticas e politicamente dominantes, neste artigo, sem novo investimento em trabalho de campo, ${ }^{2}$ poderia levar a um relativismo subjetivista, quase cínico, no qual as superposições e espelhamentos 
de identidades e deslocamentos territoriais terminariam fatalmente conduzindo a uma visão desubstancializada da situação social de milhares de pessoas que vivem e transitam por territórios limítrofes do Brasil e do Paraguai.

Recorri então à idéia de cartografia, desenvolvida por autores como Deleuze, Guattari e Boaventura de Souza Santos. Diferentemente da percepção cartesiana de um mundo passível de ser descoberto e revelado, a cartografia nos permite "fugir da confusão entre conhecimento e mundo" (Costa, 2005, p.46), onde cada mapa "serve a funções diferentes e representa coisas diversas" (ibidem).

Os "mapas" que utilizo são algumas dissertações, alguns relatórios, teses e artigos escritos desde os anos 1990, e que serão apresentados de forma a apontar para múltiplas perspectivas, fragmentos e possibilidades de compreensão. Obviamente, não se trata de uma cartografia completa. Existem muitos outros trabalhos de pesquisadores brasileiros, das mais diversas áreas, sobre brasileiros no Paraguai. Também não inclui a produção de pesquisadores paraguaios, embora o tema seja analisado há muito tempo por intelectuais de renome como Ramón Fogel, Marcial Riquelme, Domingo Laino e Tomás Palau, entre tantos outros. ${ }^{3}$ Trata-se, nesse sentido, de uma das tantas cartografias possíveis, que deve ser ampliada e modificada.

\section{Mapa 1 - Brasileiros no Paraguai como camponeses em situação de injustiça}

Cácia Cortêz é autora de um dos principais trabalhos nessa perspectiva. Trata-se do livro Brasiguaios: os refugiados desconbecidos (1994?), no qual analisa o surgimento do fenômeno dos "brasiguaios" a partir do processo de concentração de terras no Sul do país, especialmente no Estado do Paraná, e a transferência desse processo para o Paraguai a partir de facilidades oferecidas pelo governo Stroessner a grandes proprietários, companhias colonizadoras e grileiros brasileiros.

Cortêz mostra como se deu, a partir daí, a abertura de uma frente de trabalho para milhares de famílias de arrendatários, empregados rurais e pequenos proprietários agrícolas brasileiros, saídos das mais diversas regiões do país e com passagem obrigatória pelo oeste paranaense. $\mathrm{O}$ encerramento das atividades de consolidação dos grandes imóveis e problemas de legalização fundiária das pequenas propriedades levou, anos depois, a uma crise social que fez que mais de mil famílias voltassem de forma organizada ao Brasil, em dezembro de 1985, com o apoio político da Comissão Pastoral da Terra e do Movimento dos Trabalhadores Rurais Sem Terra.

A autora analisa todo o processo de organização do retorno e o cotidiano nos acampamentos e no assentamento em Ivinhema (MS). Analisa também o processo de mobilização do movimento camponês paraguaio e os conflitos que se seguiram com os brasileiros que permaneceram no país vizinho, ao mesmo tempo que identifica o cerco do Estado brasileiro às tentativas de retorno de novas famílias. 
No capítulo final, Cortêz denuncia os limites da categoria "cidadãos do Mercosul", por não incluir pequenos agricultores e demais setores empobrecidos dos estados nacionais envolvidos. Denuncia igualmente o que chama de subimperialismo brasileiro em relação ao Paraguai, e encerra seu livro anunciando a criação do "Movimento pelo Repatriamento dos Brasiguaios". Tal movimento foi o resultado da articulação de organizações camponesas dos dois países e propunha que os agricultores brasileiros sem terra que quisessem permanecer no Paraguai deveriam incorporar-se à luta dos campesinos paraguaios, ao passo que aqueles que quisessem retornar deveriam ser considerados "refugiados políticos" e solicitar apoio internacional para reingressar no Brasil. ${ }^{4}$

Na mesma linha de reflexão de Cortêz, temos a dissertação de mestrado em Geografia Humana de Luiz Carlos Batista, intitulada Brasiguaios na fronteira: caminhos e lutas pela liberdade, defendida na Universidade de São Paulo em 1990. O trabalho se destaca pela acurada análise do mercado de terras no oeste do Paraná e na fronteira leste paraguaia.

Diferentemente dos trabalhos de Cortêz e Batista, resultantes de tempos longos de pesquisa de campo e de reflexões, temos dois livros produzidos a partir de reportagens jornalísticas na Região Leste paraguaia. Carlos Wagner (1990, p.9), repórter do jornal Zero Hora, escreveu Brasiguaios: homens sem pátria, no qual pretende

mostrar as entranhas do poder político, econômico e social paraguaio e sua relação com os 350 mil camponeses brasileiros, atraídos até lá pelas promessas de terras fartas e facilidades para o trabalho. Esta atração não se deu por acaso, mas foi construída com muito carinho a partir de 1959, pelos governos do $\mathrm{Pa}-$ raguai e do Brasil. A este era interessante ter uma massa de brasileiros nas terras do país vizinho. Uma espécie de segurança para fazer o governo daquele país cumprir todos os acordos. Em especial os que envolvem a Hidrelétrica de Itaipu. Ao Paraguai interessava reter mão-de-obra altamente especializada e preços baixíssimos. E estes camponeses acabariam por colocar o Paraguai no mercado internacional de grãos [...] E o que ganharam com isso? Nada, a não ser um apelido: "brasiguaios" - homens, mulheres e crianças que vivem amedrontados diante da possibilidade de serem expulsos de uma hora para outra.

José Luiz Alves (1990), jornalista com atuação no Estado do Mato Grosso do Sul, escreveu Brasiguaios: destino incerto, em cuja contracapa destaca-se a existência de um projeto de lei em tramitação no Congresso paraguaio que delimita faixas de seguranças nas fronteiras, proibitivas a estrangeiros. Se aprovado, "mais de 300 mil brasileiros, responsáveis por $55 \%$ da economia agrícola do Paraguai podem vir a engrossar a fileira dos sem-terra no Brasil". Prossegue o texto:

Durante as ditaduras brasileira e paraguaia, nossos trabalhadores rurais, enxotados de suas áreas de produção, foram atravessando para o outro lado com vistos de permanência com duração de 30 a 90 dias. Fiéis a suas raízes e sob vistas grossas da fiscalização aduaneira, os brasileiros vêm arrastando esses prazos ao 
longo dos anos, sem a preocupação da legalidade da permanência. Com a queda das duas ditaduras e com o espírito nacionalista dominante entre os guaranis, os brasiguaios, produtores majoritários da cota de exportação de soja de um país duas vezes menor que o Estado do Mato Grosso e dono de 4,5 milhões de cabeças de gado, encontram-se, agora, na total dependência dos dois governos, podendo perder de uma hora para outra tudo que levaram 15, 20 anos para conquistar. (Alves, 1990, contracapa)

Trabalhos como os de Wagner e Alves ajudaram a construir a noção midiática de "problema brasiguaio" ou de "questão brasiguaia". Como afirma Champagne (1997, p.63), os mal-estares sociais apenas passam a ter uma existência visível quando falados na mídia. A partir desse momento, sofrem deformações porque "longe de se limitar a registrá-los, o tratamento jornalístico fá-los experimentar um verdadeiro trabalho de construção, que depende muito amplamente dos interesses próprios deste setor de atividade".

Segundo o sociólogo francês, as pesquisas jornalísticas, fruto de um breve trabalho de campo, acabam muito mais próximas de uma investigação policial ou judiciária do que de uma pesquisa sociológica. A concorrência, por sua vez, tende a estimular abordagens sensacionalistas. Muitos jornalistas que se sentem úteis por denunciarem a violação de direitos de um determinado grupo social, paradoxalmente, correm o risco de contribuir para sua estigmatização.

E uma vez construída uma representação social pela mídia, ela tende a perdurar mesmo com desmentidos e correções posteriores, isso porque "ela nada mais faz, na maioria das vezes, que reforçar as interpretações espontâneas e mobiliza, portanto, os prejulgamentos e tende, por isso, a redobrá-los” (ibidem, p.64).

Nessa visão midiática, em que os “brasiguaios”, entendidos como unidade de análise, são também apresentados como vítimas de injustiça, transparece um olhar extremamente elitista, etnocêntrico e preconceituoso em relação ao povo e à nação paraguaios, de tal forma naturalizado que persiste, sem constrangimentos, nos noticiários atuais. ${ }^{5}$

\section{Mapa 2 - Brasileiros no Paraguai como grupo étnico em situação de fronteira}

Em minha dissertação de mestrado, intitulada Brasiguaios: conflito e identidade em fronteiras internacionais (Sprandel, 1992), analisei o surgimento da identidade "brasiguaios" a partir da mobilização política de famílias camponesas que retornaram organizadamente ao Brasil em 1985, no início da Nova República. Por meio das noções e dos conceitos de etnicidade e nação, analisei as relações dos grupos familiares que assim se identificavam com os aparelhos de poder e com mediadores externos que intermediavam sua relação com a sociedade nacional.

Optei pelo estudo da situação por meio de noções e conceitos referentes a grupos étnicos e suas fronteiras, uma vez que me pareceu que pensá-la como imigração ou como parte do processo de mobilização camponesa que ocorria então 
em todo o Brasil não contemplaria sua complexidade. Mesmo para aqueles que optaram por uma estratégia de adaptação que implicava registro dos filhos como cidadãos paraguaios e aprendizado das línguas oficiais do país, o Paraguai não foi exatamente um país escolhido para emigrar. A opção pelo Paraguai parece ter se configurado antes como possibilidade de acesso a novas áreas de terras agriculturáveis, da melhor qualidade, pelas condições facilitadas. Essas terras situamse muito próximas ao Brasil, e esse se faz presente nas transmissões de rádio e televisão. Além disso, é permanente o contato social e econômico com cidades paranaenses e sul-mato-grossenses, limítrofes.

Ao fazer pressão, entretanto, sobre o território brasileiro, e não sobre um imóvel rural específico, os grupos familiares que se identificaram como "brasiguaios" inseriram-se de forma distinta no conjunto de mobilizações camponesas pela terra. Sua ênfase na nacionalidade brasileira e na denúncia de situações de injustiça vividas no Paraguai, embora não se caracterizassem como conflitos étnicos com a população paraguaia, revelava a utilização de elementos e categorias étnicas na condução das diversas etapas de uma mobilização que ficou registrada como um dos principais conflitos pela posse da terra da época.

Em minha análise, pude verificar que, sob a hegemonia que a identidade "brasiguaios" procurava traduzir, eram divisíveis grupos familiares de naturalidades diferentes (unidades da federação) e de condições econômicas (pequenos proprietários, arrendatários, posseiros e assalariados rurais) diversas. A unidade era acionada a partir do momento que estavam mobilizados politicamente para fora. Teoricamente, trabalhei com os conceitos de grupo étnicos e fronteiras étnicas, estudados por Frederik Barth, que permitem que possamos diferenciar internamente o grupo em estudo sem descaracterizá-lo como tal, percebendo as diferentes estratégias de navegabilidade social que utilizam.

Depois de discutir a construção da identidade "brasiguaios" a partir dos documentos que esses enviaram aos órgãos oficiais, incorporei à análise as histórias de vida e a etnografia do cotidiano de alguns grupos familiares ligados às "lideranças" do movimento. Meu trabalho de campo aconteceu cinco anos depois da mobilização pela terra, quando já estavam assentados no Projeto de Assentamento Novo Horizonte, em Ivinhema (MS). Como resultado, coletei narrativas diversas sobre a decisão de transferir-se para o Paraguai e sobre os anos vividos naquele país. Tais narrativas relativizam os documentos e depoimentos produzidos no "tempo do acampamento". Da mesma forma, a observação da intensa movimentação entre o assentamento e cidades paraguaias relativiza a idéia de "terra prometida" e aponta para uma percepção da mobilização dos chamados "brasiguaios” como parte de estratégias familiares para reprodução econômica e social. ${ }^{6}$

\section{Mapa 3 - Brasileiros e paraguaios em situação de interação: a dinâmica das identidades nacionais}

A tese de doutorado em Sociologia Fronteiras em movimento e identidades nacionais - a imigração brasileira no Paraguai, de José Lindomar Coelho Al- 


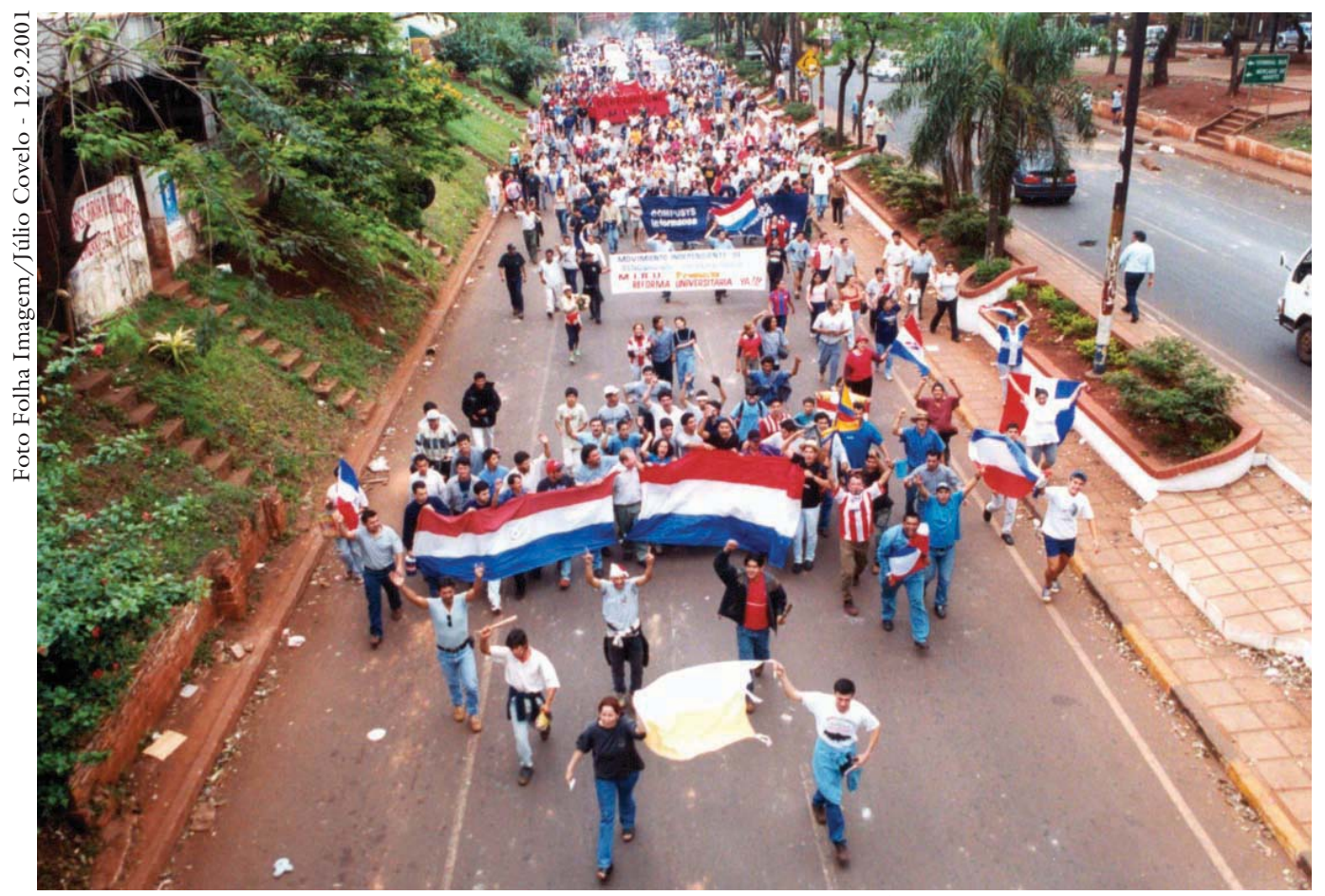

Manifestação a favor de mais vagas para paraguaios no comércio da fronteira com o Brasil.

buquerque, defendida em 2005 na Universidade Federal do Ceará, além de um levantamento cuidadoso sobre o número de brasileiros no Paraguai, seus fluxos migratórias e sua estratificação social, analisa o desenvolvimento econômico das áreas de colonização brasileira, o aumento do poder político dos brasileiros e a influência cultural brasileira na zona de fronteira. O autor também analisa os conflitos de terra envolvendo campesinos e brasileiros e as disputas em torno da aprovação de uma nova lei de segurança nas fronteiras (com a versão de brasileiros e paraguaios sobre tais temas).

À análise da importância simbólica das imagens do passado nos conflitos do presente (percepção dos brasileiros como "novos bandeirantes", representações e versões da "Guerra do Paraguai", a imigração brasileira como herança de Stroessner etc.), Albuquerque acrescenta os conflitos cotidianos entre brasileiros e paraguaios baseados sobretudo em distintas noções de trabalho.

O autor realizou seu trabalho de campo nas cidades de Santa Rita, Santa Rosa, San Alberto, Mbaracayu (Departamento Alto Paraná), Salto del Guayra (Canindeyu) e Pedro Juan Caballero (Amambay), e verificou como as identificações nacionais e étnicas são estabelecidas e acionadas a todo o instante nas regiões de fronteira: brasileiro, paraguaio, brasiguaio, imigrante, nativo, estrangeiro, cidadão, colono brasileiro, descendente de alemão, paraguaio legitimo e puro etc.

Nessa mesma linha de identificação de jogos identitários na interação entre brasileiros e paraguaios na fronteira leste paraguaia, temos a dissertação de mestrado Des-caminhos brasileiros em terras paraguaias, de Marcelo Santa Bárbara, defendida em 2005 no Departamento de Geografia da Universidade Federal 


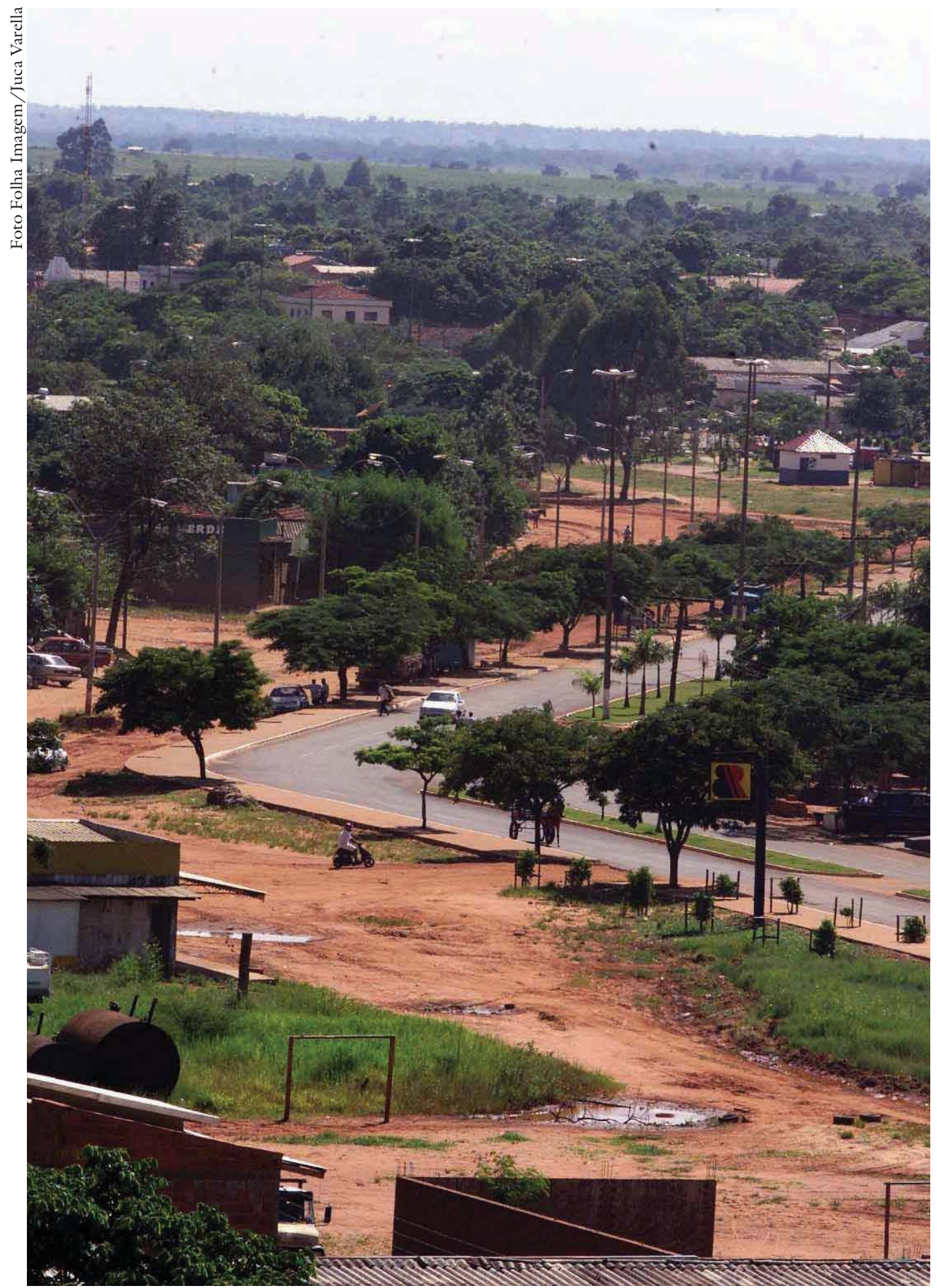

A fronteira do Brasil com o Paraguai é demarcada por uma rua asfaltada. Do lado esquerdo da pista, fica a paraguaia Capitán Bado; do direito, Coronel Sapucaia (MS).

Fluminense. O trabalho de Santa Bárbara (2005a) traz para nossa cartografia a idéia de que existem diferentes níveis de territorialização entre o que chama de "classes dominantes" e "imigrantes ilegais". Para o primeiro grupo, que tem sua 
situação migratória regularizada (muitos já sendo cidadãos paraguaios), haveria uma grande mobilidade transfronteiriça, ligada à sua inserção a circuitos comerciais, financeiros e políticos da região e mesmo do Hemisfério Norte. ${ }^{7}$

\section{Mapa 4 - A geografia e formação de um "espaço brasiguaio"}

Sylavain Souchard, doutor em Geografia pela Université de Poitiers com a tese La formation d'un espace brésiguayen dans l'Est du Paraguay. Migrations pionnières brésiliennes et organisations socio-spatiales dans l'Oriente du Paraguay (2001), defende a existência de um novo espaço na América do Sul, a fronteira paraguaia-brasileira. Segundo ele, na fronteira leste do Paraguai, os brasileiros estruturaram um espaço original, chamado de "brasiguaio": um espaço que já não é totalmente paraguaio, tampouco é uma mera extensão do oeste do Brasil meridional, um território de contato entre estruturas territoriais locais, nacionais, macrorregionais e até mundiais. Sua tese foi publicada na França, em 2002, com o título Pionniers brésiliens au Paragnay. Em seu trabalho, afirma que a colonização brasileira favorece a integração econômica e política do Paraguai, ao mesmo tempo que aprofunda sua dependência externa. Souchard entende que a região de fronteira é hoje o principal ponto de discussão sobre o lugar do Paraguai no Mercosul.

\section{Mapa 5 - Brasileiros no Paraguai como grupo lingüístico}

A lingüística tem estudado os brasileiros no Paraguai do ponto de vista dos contatos lingüísticos. Destacam-se os artigos de Wolf Dietrich ("Os brasiguaios no Brasil: aspectos fonéticos e gramaticais"), de Haralambos Symeonidis ("Os brasiguaios no Brasil: o uso das preposições com o verbo ir") e de Harald Thun ("Os brasiguaios no Paraguai: o comportamento lingüístico dos brasileiros que vivem no Paraguai, segundo os materiais do Atlas Lingüístico Guarani-Românico"). Esses artigos estão publicados no livro O português do Brasil. Perspectivas da pesquisa atual, organizado pelos pesquisadores da Universität Münster Wolf Dietrich e Volker Noll, publicado em 2004, na Europa.

No Brasil, temos a tese de doutorado de Maria Elisa Pires Santos, O cenário multilingüe/multidialetal de fronteira e o processo identitário de alunos brasiguaios no contexto escolar, defendida em 2004, na Unicamp. Os alunos estudados por Santos são filhos de brasileiros que migraram para o Paraguai e retornaram para o Brasil, fixando-se em Foz do Iguaçu e cidades vizinhas. Esses alunos, que têm como primeira língua o português (e/ou outra língua como o alemão, italiano ou polonês), foram alfabetizados no Paraguai na língua espanhola e guarani. Ao retornarem, precisam dar conta da língua portuguesa escrita, que não dominam. O objetivo desse trabalho foi investigar como a interação construída em atividades de letramento interfere no processo identitário do aluno "brasiguaio", em contexto escolar multilíngüe rural. Como resultado de sua abordagem, Santos pretendeu trazer à tona a complexidade inerente à denominação "brasiguaio". Além disso, seu trabalho permite ir além da compreensão de que apenas as relações desiguais de poder são reveladas nas práticas discursivas das 
crianças. Existiriam também interstícios nos quais há espaço para a resistência e para o engendramento de novos modos de vida.

\section{Mapa 6 - Outras perspectivas acadêmicas}

$\mathrm{Na}$ Antropologia, temos o trabalho de Fernando Rabossi, fundamental para uma melhor compreensão do comércio entre Foz do Iguaçu (Brasil) e Ciudad del Este (Paraguai), que resultou na tese de doutorado Nas ruas de Ciudad del Este: vidas e vendas num mercado de fronteira, defendida em 2005, no Museu Nacional. $\mathrm{O}$ autor analisa a fronteira em questão (especialmente no que se refere às dinâmicas espaciais e temporais) como um espaço de inter-relações que se estrutura a partir de diferenças. Do mestrado em Integração Latino-Americana, da Universidade Federal de Santa Maria (Rio Grande do Sul), temos a dissertação Uma análise crítica da transferência de presos entre o Brasil e o Para-guai (2003), de Donária Silvia de Camargo Sannazzaro Smith, que analisa o tratado de transferência de presos entre o Brasil e o Paraguai, à luz dos direitos humanos.

\section{Mapa 7 - Brasileiros no Paraguai como brasileiros no exterior}

Na década de 1990, milhares de brasileiros deixam o país em busca de trabalho no Hemisfério Norte. Essa nova realidade levou ao surgimento das categorias "brasileiros no exterior" e "emigração brasileira", nas quais os brasileiros que vivem no Paraguai foram incorporados. ${ }^{8}$ Seus deslocamentos populacionais, no entanto, diferenciam-se daqueles realizados para os Estados Unidos, Europa, Japão e outros países de além-mar em, no mínimo, dois pontos: vêm acontecendo há cerca de trinta anos para países limítrofes e os emigrantes são basicamente agricultores ou pessoas que realizam atividades acessórias ao mundo camponês.

Estudar esse tipo de emigração no contexto maior do fenômeno "emigração brasileira" contemporânea levou a uma ampliação dos elementos de reflexão. À realidade localizada das "linhas", "colônias", "pueblos" ou "bairros" dos brasileiros em países limítrofes, foi preciso acrescentar dados sobre as reivindicações e as mobilizações de outras comunidades brasileiras no exterior (a maioria delas no Hemisfério Norte) e incorporar toda a discussão sobre as migrações internacionais no século XXI. ${ }^{9}$

Pode-se dizer, entretanto, que os brasileiros no Paraguai (assim como aqueles que vivem ou transitam por territórios de países limítrofes) configuram uma espécie de "brasileiros no exterior" de segunda categoria, cujo valor é mais numérico (segundo o Itamaraty, é o segundo maior grupo de brasileiros no exterior, suplantado apenas pelos brasileiros que vivem nos Estados Unidos) do que político. ${ }^{10}$ As poucas iniciativas de defesa de interesses de "brasileiros no exterior" ou de criação de políticas públicas para o atendimento de suas necessidades são pensadas sobretudo tendo em vista os brasileiros no Hemisfério Norte.

Recentemente, em seminários realizados com representantes de mais de trinta municípios do oeste paranaense (e um do Mato Grosso do Sul), ${ }^{11}$ verifiquei que praticamente a totalidade desses municípios tinha moradores vivendo 
no Paraguai, ao mesmo tempo que recebia demandas de brasileiros residentes no país vizinho (especialmente nas áreas de saúde e assistência social). A grande maioria desses municípios também tem registro de população vivendo no $\mathrm{He}$ misfério Norte. É muito provável que investimentos em trabalho de campo na região encontrem grupos familiares com parte de seus integrantes vivendo no Paraguai e outros vivendo em Portugal, por exemplo.

Avançar por essa linha de pesquisa poderia identificar se a emigração para o Hemisfério Norte representa uma forma de manutenção da condição camponesa de integrantes do grupo familiar que permaneceram no Brasil. Demonstra, de antemão, que a necessidade de sobrevivência e os processos de atração têm levado para muito mais longe uma população que tradicionalmente seguia apenas as "frentes de expansão" ou as "frentes pioneiras" da região.

\section{Mapa 8 - Brasileiros no Paraguai do ponto de vista de políticas públicas}

No artigo inédito "Políticas públicas para o atendimento das demandas de cidadãos brasileiros no exterior - primeiras observações" (Sprandel \& Schelb, 2003), que escrevi com a colaboração do Procurador da República Guilherme Zanina Schelb, percebe-se que os brasileiros no exterior têm demandado do governo brasileiro, em diversos momentos históricos, terras, documentação e regularização da sua situação migratória, repatriamento, atendimento a presos e detidos, politicas públicas e direito de representação política. Ao fazê-lo, mobilizaram o Poder Executivo, seus órgãos de segurança pública, seus órgãos fundiários, sua diplomacia e - mais recentemente - o Ministério da Justiça, o Ministério Público e os órgãos oficiais ligados à área de direitos humanos. Também são demandados ou agem como mediadores o Poder Legislativo (federal e estaduais), as igrejas, os movimentos sociais e as entidades de defesa dos direitos humanos.

Em relação aos brasileiros que vivem no Paraguai, nas décadas de 1970 e 1980, seus problemas eram analisados à luz de uma matriz militar. A geopolítica era padrão de pensamento consagrado e servia de justificação para políticas públicas, notadamente a de ocupação das fronteiras nacionais com população civil. A ação do governo militar sobre os territórios brasileiros fronteiriços, considerados de "segurança nacional", foi intensa. Entre 1972 e 1975, apenas nos estados do Mato Grosso do Sul e Paraná, atingiu 167.034 hectares, sob a forma de Projetos Integrados de Colonização. Tais projetos, consoante documentos oficiais, objetivavam "resolver problemas de tensão social envolvendo agricultores, bem como propiciar a ocupação racional de áreas estratégicas para o desenvolvimento nacional" (Meaf, 1984, p.6).

A construção de hidroelétricas, parte dessa estratégia geopolítica, acabou tendo papel importante na transferência de milhares desses brasileiros para o Paraguai. Quando parte deles começou a retornar, nos anos 1980, o que estava em questão era a necessidade de terras. Mas para resolver o problema foram acionadas, além dos órgãos fundiários, as forças de segurança. Mesmo a redemocrati- 


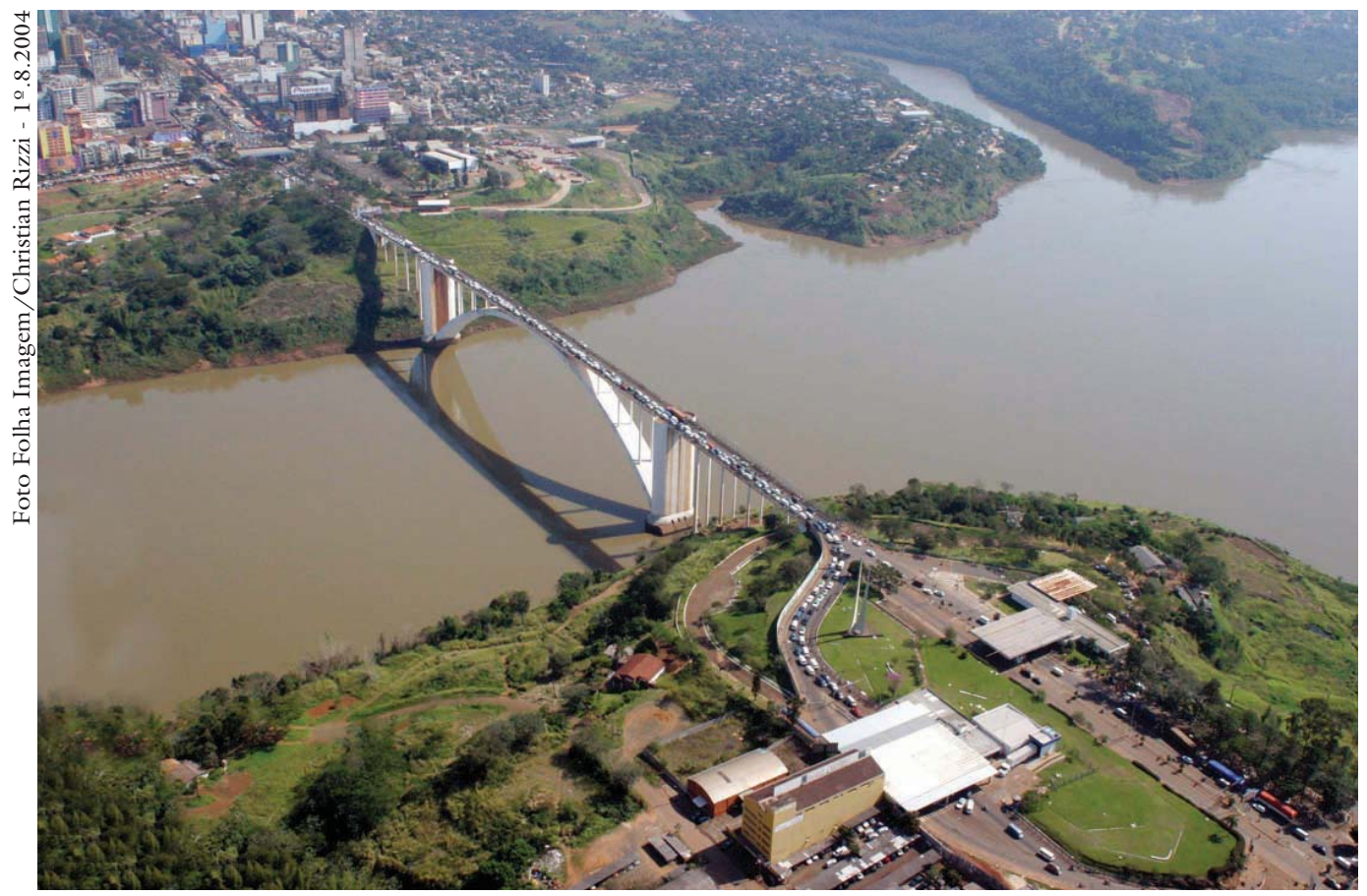

Vista aérea da Ponte da Amizade, que liga o Brasil ao Paraguai (ao fundo).

zação do país, iniciada em 1985, não significou o abandono de velhos padrões. A novidade foi a valorização da diplomacia para a resolução dos conflitos.

A via diplomática, ao atuar na mediação com o governo paraguaio, só pôde avançar no sentido de defender a necessidade de cadastramento de brasileiros em território paraguaio e da regularização de sua documentação pessoal e situação migratória. Quando aos brasileiros no Paraguai se somaram milhares de outros que emigraram para o Hemisfério Norte, o governo brasileiro, por intermédio do Itamaraty, decidiu investir na assistência e proteção ao cidadão brasileiro no exterior. Para tanto, o Ministério das Relações Exteriores implantou um conjunto de medidas: a criação de Conselhos de Cidadãos; a instituição de consulados itinerantes; a modernização e extensão da rede consular brasileira; o treinamento de pessoal e a edição de cartilhas consulares.

Tais medidas pouco afetaram os brasileiros que vivem no Paraguai. Também foram consideradas insuficientes pelas comunidades organizadas de brasileiros no exterior, como a Casa do Brasil de Lisboa, que exigem do Estado brasileiro políticas mais amplas para o atendimento de suas demandas nas áreas de negócio, saúde, trabalho, previdência social, representação política etc.

Os brasileiros que vivem no Paraguai, no entanto, não têm participado dessa mobilização. Não estavam presentes no I Simpósio Internacional sobre Emigração Brasileira (promovido pela Casa do Brasil de Lisboa, em 1997) nem no I Encontro Ibérico da Comunidade de Brasileiros no Exterior (em 2002, também em Lisboa, com o apoio do Ministério Público Federal). Foi deliberação desse último evento que o Estado brasileiro deveria garantir aos emigrantes direitos de cidadania, por meio de políticas públicas voltadas para sua defesa. 
No momento, a comunidade organizada de brasileiros no exterior ainda aguarda a definição de uma instância governamental para atender às suas demandas. Uma vez criada, essa instância oficial deverá ter a sensibilidade para entender as diferenças regionais, para que os brasileiros que vivem no Paraguai ou outros países limítrofes recebam um tratamento específico.

\section{Mapa 9 - Os brasileiros que vivem no Paraguai e os organismos internacionais}

O fato de viverem na tríplice fronteira complexifica ainda mais as já multifacetadas representações sobre os brasileiros que estão no Paraguai. Para começar, trata-se de uma região que vem sendo insistentemente acusada de acobertar ou financiar terroristas internacionais. Nela, organismos internacionais como a Organização Internacional do Trabalho (OIT), o Fundo das Nações Unidas para a Infầncia (Unicef) e a Organização Internacional para as Migrações (OIM) têm investido em projetos de combate à exploração sexual comercial de crianças e adolescentes, ao tráfico de seres humanos e em diagnósticos da situação de crianças e adolescentes nos mais diversos aspectos. ${ }^{12}$

Em tais estudos, fica evidente a intensa circulação de pessoas na região:

Faz parte da estratégia de sobrevivência de muitas famílias, que vivem na região em estudo, a procura por serviços ou trabalho no outro lado da fronteira, sempre que consideram que ali terão melhores possibilidades de assistência social básica ou melhores empregos. Como exemplo, pode-se citar o caso de brasileiros que trabalham no comércio de Ciudad del Este ou nas áreas agrícolas dos departamentos paraguaios e argentinos selecionados. Há o registro, igualmente, de brasileiros que procuram em Misiones remédios ambulatoriais gratuitos oferecidos pelo Plan Remediar. Inversamente, verifica-se a procura, por paraguaios e argentinos, de testagem e tratamento gratuito para Aids no Brasil. São inúmeras as situações de brasileiros que vivem na Argentina ou no Paraguai e que matriculam seus filhos em escolas brasileiras ou que procuram no Brasil serviços gratuitos de saúde. Todas essas situações, como veremos mais adiante, apontam para uma grande circulação de pessoas (inclusive crianças e adolescentes) entre os três países, que precisa ser melhor estudada. (Unicef, 2005, p.17-8)

O estudo do Unicef demonstra que a construção de políticas públicas eficientes nas áreas socioeconômica ou de segurança precisa levar em consideração que a tríplice fronteira é uma região formada por pessoas que pertencem a diferentes nacionalidades, etnias e culturas e que estão permanentemente envolvidas em movimentos migratórios:

Paraguai e Argentina têm presença significativa de crianças e adolescentes que migram com suas famílias de países limítrofes (brasileiros e argentinos no Paraguai e paraguaios e brasileiros na Argentina) [...] Nos municípios brasileiros selecionados [...] é grande a demanda de brasileiros que vivem no Paraguai, os chamados brasiguaios, residentes principalmente nos departamentos de Alto Paraná e Canindeyú. Famílias de brasiguaios, muitas vezes acompanhadas de crianças e adolescentes, procuram no Brasil atendimento nos serviços públicos 
de saúde (inclusive atendimento neonatal), educação e assistência social. Também é comum a procura por assistência jurídica, documentação (inclusive registro de nascimento) e aposentadoria, além da procura por empregos, comércio, terras e moradia. Na região também se verificam deslocamentos sazonais de famílias para outras regiões agrícolas do país, para pólos industriais regionais e para países do hemisfério norte, especialmente Estados Unidos, Inglaterra, Japão e Portugal [...] Nos departamentos paraguaios selecionados, além de considerável população de migrantes internos, vivem muitos estrangeiros. Esses são majoritariamente brasileiros e estão distribuídos por vários municípios, especialmente Santa Rita, Santa Rosa del Monday, Hernandarias, Ciudad del Este, Minga Porá, Mbaracayú e Salto del Guairá. (ibidem, p.20-1)

A Organização Internacional do Trabalho (OIT), por meio do Programa de Eliminação do Trabalho Infantil, selecionou a tríplice fronteira para implementar um de seus programas mundiais de combate à exploração sexual comercial de crianças e adolescentes. Um dos motivos para isso foi o entendimento de que se tratava de região marcada pela presença do crime organizado e do tráfico internacional de drogas, armas e seres humanos. De setembro de 2001 a meados de 2005, com o financiamento do Departamento do Trabalho dos Estados Unidos, a OIT implementou nos municípios de Puerto Iguazú (Argentina), Foz do Iguaçu (Brasil) e Ciudad del Este (Paraguai) o Programa de Prevenção e Eliminação da Exploração Sexual de Crianças e Adolescentes na Fronteira Argentina/Brasil/Paraguai.

O programa identificou lacunas legais e propôs harmonizações entre os três países; contribuir na obtenção e análise de informações confiáveis e relevantes sobre a exploração sexual comercial de crianças e adolescentes; fortalecer as instituições públicas e privadas na formulação e implementação de ações para eliminar o problema; proporcionar atenção nas áreas de saúde, educação, apoio psicossocial e jurídico a crianças e adolescentes sexualmente exploradas e contribuiu na formulação de políticas e mecanismos de prevenção.

Numa avaliação final do Programa, fica claro o quanto a sociedade local foi contaminada e respondeu positivamente às demandas de transformação de uma realidade apresentada de forma extremamente negativa:

O Programa de Prevenção e Eliminação da Exploração Sexual de Crianças e Adolescentes na Fronteira Argentina/Brasil/Paraguai teve repercussões locais, nacionais e internacionais [...] Sobretudo, o projeto da Tríplice Fronteira passou a ser visto como uma forma de se trabalhar em fronteira, com outros países [...] Para as populações locais, houve o reconhecimento da força da mobilização, como no ato de ocupação da Ponte da Amizade [...] A articulação entre operadores de direito foi fundamental para que a discussão sobre exploração sexual comercial de crianças e adolescentes e tráfico de seres humanos passasse a incorporar a percepção da migração como um direito. A partir das avaliações feitas pelos próprios atores nos relatórios lidos e nas entrevistas, acrescidas de nossas reflexões, entendemos que a grande lição aprendida foi a conscientização de que é possível deslocar o Estado de sua centralidade para que a sociedade possa atuar considerando os recursos disponíveis, atuais e potenciais. A título de 
conclusão, é possível afirmar que a Região da Tríplice Fronteira, em Ciudad del Este (Paraguai), Foz do Iguaçu (Brasil) e Puerto Iguazú (Argentina) tem hoje um marco de humanidade, solidariedade e desenvolvimento na direção de um futuro melhor, mais justo e harmônico para estas e para as futuras gerações de crianças e adolescentes. (Guimarães \& Sprandel, 2005, p.161-4)

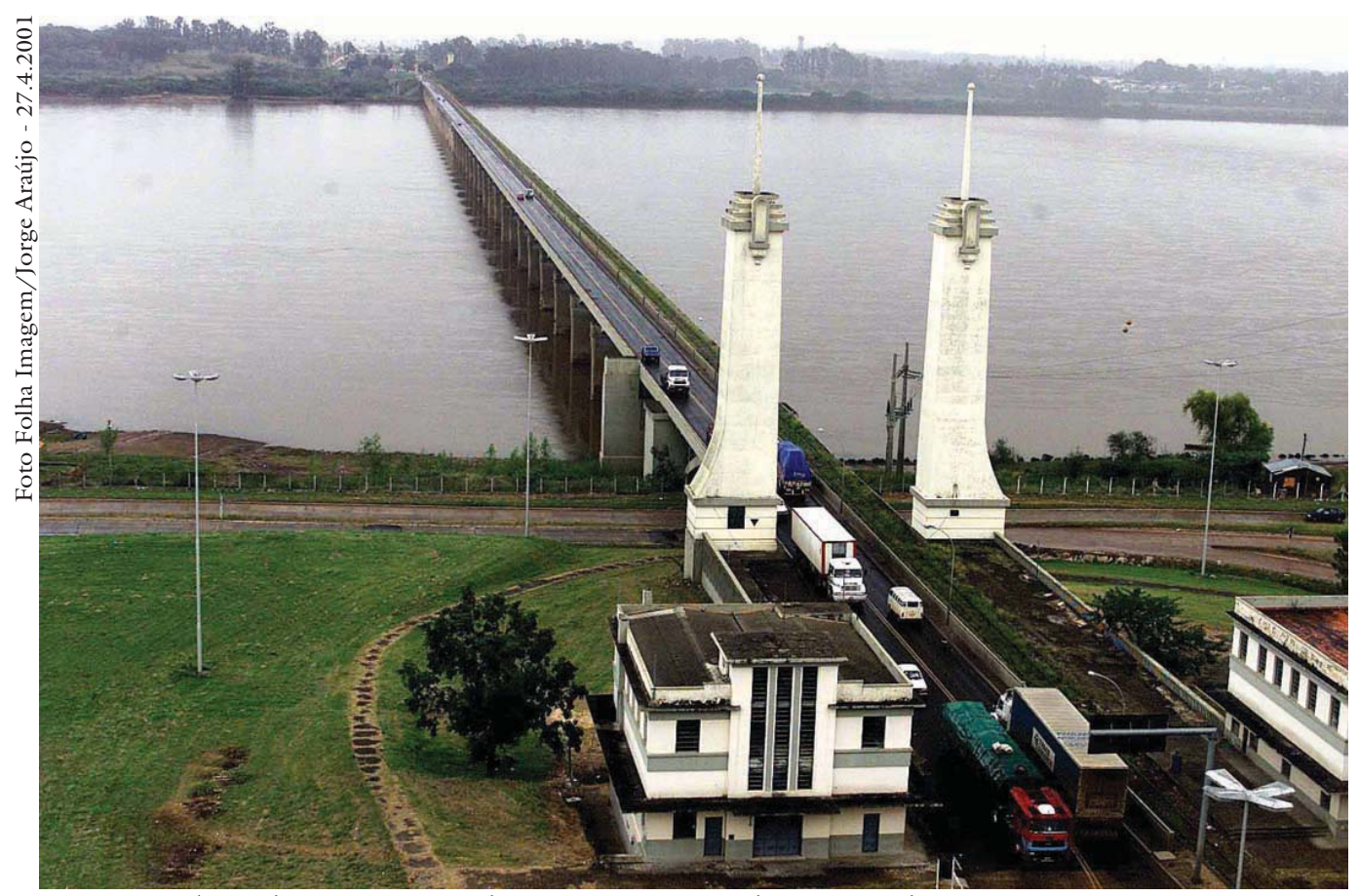

Vista aérea da Ponte Presidente Vargas, que liga Paso de Los

Libres a Uruguaiana (RS), fronteira do Brasil com a Argentina.

No livro La trata de personas en el Paraguay, a OIM (2005) identificou um fluxo de tráfico proveniente de Foz de Iguaçu, tendo como destino Ciudad del Este e as colônias agrícolas brasileiras próximas. $\mathrm{O}$ documento faz referência a vários casos de adolescentes brasileiras procedentes do Paraná e do Rio Grande do Sul, encontradas em prostíbulos das colônias brasileiras de San Alberto, Santa Rita, Katueté e outras. O estudo da OIM constatou que das cidades de Caaguazú, Ciudad del Este e Hernandarias também saem crianças e adolescentes para as colônias brasileiras de Santa Rita, San Alberto, Katueté, Mbaracayú e outras zonas de agricultura extensiva .

Embora as organizações citadas percebam os brasileiros que vivem no Paraguai e transitam pela tríplice fronteira sob uma perspectiva humanitária, na qual prevalece a valorização de atores e programas locais, o cenário internacional aponta para outra direção. A migração internacional tem sido tratada preferencialmente no âmbito dos acordos de segurança pública. A Convenção das Nações Unidas contra o Crime Organizado Internacional (Convenção de Palermo), de 2000, e seus protocolos adicionais sobre Tráfico de Migrantes e Tráfico de Seres Humanos foram ratificados por dezenas de países. A Convenção de Palermo entrou em vigor em 20 de setembro de 2003, o Protocolo sobre Tráfico de Mi- 
grantes, em 28 de janeiro de 2004, e sobre Tráfico de Seres Humanos, em 25 de dezembro de 2003. Enquanto isso, a Convenção Internacional sobre Trabalhadores Migrantes e suas Famílias, de 1990, que defende os direitos humanos dos migrantes, entrou em vigor apenas em $1^{\circ}$ de julho de 2003 e foi ratificada por somente 22 países.

Essa tendência de criminalização das migrações em geral, e da região da tríplice fronteira, em particular, é um dos aspectos mais preocupantes e de mais difícil análise desse "lugar difícil" onde vivem milhares de brasileiros e seus descendentes. ${ }^{13}$ Nesse sentido, a atuação de organismos internacionais como a OIT e o Unicef, que trabalharam diretamente com governantes locais e com a sociedade civil organizada, tem sido fundamental para estabelecer processos mútuos de conhecimento, trocas de experiências e ações conjuntas. Ao fazê-lo, retiram argumentos daqueles que insistem em “demonizar” a região.

\section{Observações finais}

Da análise dessa pequena cartografia aqui apresentada, surgem mais questões do que respostas. Quais as possibilidades para resolução de um "problema brasiguaio"? Quais os desdobramentos da "questão brasiguaia"? Será uma reforma agrária no Brasil? Será uma reforma agrária no Paraguai? Será um aumento no controle das fronteiras? Será a transnacionalização de programas sociais que beneficiem os milhares de "brasiguaios" empobrecidos e explorados? Será um acordo bilateral de regularização migratória? Seria a ampliação dos direitos políticos dos brasileiros no exterior, com a possibilidade de elegerem seus representantes para a Câmara dos Deputados? Será a entrada em vigor da livre-circulação prevista nos acordos do Mercosul? Será o desenvolvimento de um sentimento nacional paraguaio entre os descendentes de brasileiros que vivem no país vizinho?

A busca de respostas ou o refinamento de perguntas está presente em cada um dos trabalhos aqui citados ou analisados. Como desafio, talvez precisemos saber identificar melhor o significado de certos silenciamentos. Diante de tão fragmentada situação social, não se percebe claramente qual a posição de setores importantes dos governos dos dois países. Tampouco fica claro o que pensam setores influentes da comunidade de brasileiros no Paraguai e de empresários e grandes comerciantes paraguaios. $\mathrm{O}$ que pensam os comerciantes e as autoridades locais de municípios brasileiros limítrofes? O que pensam os desempregados que perambulam pelas fronteiras atrás de trabalhos informais? Em que situação estão os pequenos proprietários e arrendatários? O que têm dito as lideranças do movimento campesino paraguaio? E os ambientalistas do país vizinho?

Também precisamos identificar melhor o significado das insistentes, monótonas e pouco brilhantes referências aos brasileiros no Paraguai em locais de decisão política. Recentemente, no Senado Federal, em Brasília, o chanceler brasileiro Celso Amorim falava sobre a nacionalização dos hidrocarburetos na Bolívia e o anúncio de uma reforma agrária nos departamentos fronteiriços de Pando e Santa Cruz, onde estão produtores de soja brasileiros. 
Mais de um dos senadores presentes aventou a hipótese de que o mesmo poderia acontecer no Paraguai, com a nacionalização de Itaipu e a expulsão dos "brasiguaios". Embora se tratasse de um argumento sobretudo ideológico (uma crítica à política externa do governo), chama a atenção que os "brasiguaios" sejam mais uma vez acionados de forma homogênea, quase como um bloco opaco de pessoas que poderia ser deslocado de um lado para o outro do tabuleiro geopolítico do Cone Sul. O que está por trás desse renascimento (ou retorno à superfície) da percepção dos brasileiros no Paraguai como questão de segurança nacional? O que há em comum entre os “sojeros” brasileiros no Paraguai e na Bolívia? Quais seus interesses e quais seus compromissos com os países onde se instalam? Que relações constroem com as populações locais? Que elementos étnicos e nacionais estão envolvidos nas nossas percepções em relação ao Paraguai e à Bolívia?

Para Bourdieu (1997), os lugares difíceis, como a fronteira Paraguai/Brasil, são antes de tudo difíceis de descrever e difíceis de pensar. Diante de imagens simplistas e unilaterais sobre estes lugares, sugere sua substituição "por uma representação complexa e múltipla, fundada na expressão das mesmas realidades em discursos diferentes, às vezes inconciliáveis" (ibidem, p.11). Procurei, neste artigo, identificar alguns dos pesquisadores que estão envolvidos na difícil tarefa de escutar (e traduzir) a pluralidade de perspectivas em jogo. Cada um, com seus pequenos mapas, ajuda a compor uma cartografia que busca corresponder à pluralidade de pontos de vista coexistentes na região e que são, muitas vezes, diretamente concorrentes.

Todos, à sua maneira, buscaram ir além das aparências para remontar aos verdadeiros determinantes econômicos e sociais que estão por trás dos "malestares sociais" e da construção de "lugares difíceis". Por trás de tantas tarefas e tantos desafios, a esperança no que Bourdieu via como uma possibilidade da reflexão sociológica: levar à consciência os mecanismos que tornam a vida dolorosa. "O que o mundo social faz, o mundo social pode, armado deste saber, desfazer” (Bourdieu, 1997, p.735).

Notas

1 Note-se que a própria categoria "brasileiros no Paraguai", que uso de forma naturalizada neste artigo, deve ser relativizada, pois inclui filhos e netos de cidadãos brasileiros que já nasceram em território paraguaio e foram registrados naquele país.

2 Realizei trabalho de campo entre brasileiros que vivem ou viveram no Paraguai no começo da década de 1990, como parte de meu mestrado em antropologia social (Sprandel, 1992).

3 São exemplos da valiosa contribuição paraguaia ao tema publicações como Paraguai: fronteiras e penetração brasileira, de Domingo Laino (1979); o artigo "Brasiguaios", de Tomás Palau, publicado em Migrações Internacionais, contribuições para políticas (2001) e Enclave sojero: merma de soberania y pobreza, organizado por Fogel \& Riquelme (2005). 
$4 \mathrm{O}$ movimento teria vida curta, atropelado pelas pautas e urgências dos movimentos camponeses dos dois países e prejudicado pela força da questão nacional na mobilização paraguaia.

5 Esse mesmo tipo de representação reapareceu recentemente, com toda a força, nas reportagens, editoriais e artigos jornalísticos que analisaram a nacionalização dos hidrocarburetos na Bolívia. Sobre a percepção do Brasil em relação ao Paraguai, ver Sprandel (1997).

6 Considero esse aspecto da dissertação minha melhor contribuição para o entendimento dos deslocamentos fronteiriços na região. Para uma análise resumida do tema, ver Sprandel (2004).

7 As principais linhas analíticas da dissertação foram publicadas no artigo "Brasiguaios: territórios e jogos de identidades" (Santa Bárbara, 2005b).

8 A Comissão Nacional de População e Desenvolvimento publicou, em 2001, o livro Migrações Internacionais - Contribuições para politicas. Nele, os brasileiros no Paraguai são analisados no capítulo "Brasileiros no exterior", pelo sociólogo paraguaio Tomás Palau (2001).

9 Analiso essa mudança de enfoque no artigo "A terra é estrangeira, mas a da minha roça é igual: terras e territórios no cotidiano de camponeses brasileiros emigrantes" (Sprandel, 1998).

10 Embora no contexto local e regional seja distinto. Os brasileiros que vivem em Santa Rita, no Paraguai, por exemplo, têm maior poder de pressão política sobre instâncias decisórias (governos municipais/ estaduais e parlamentares) do que os brasileiros que estão em Boston ou Lisboa. Isso pode ser explicado por dois motivos: a proximidade física e a potencial capacidade de participação nos processos eleitorais, uma vez que muitos mantêm seus títulos de eleitor brasileiros.

11 Os seminários foram realizados no segundo semestre de 2005 nas cidades paranaenses de Toledo e Foz do Iguaçu, como parte integrante de um diagnóstico da situação da criança e do adolescente na Tríplice Fronteira, promovido pelo Fundo das Nações Unidas para a Infância (Unicef).

12 Alguns dos resultados desses investimentos dos organismos internacionais na região podem ser consultados em: <http://www.oit.org.pe/ipec/esci/documentos/esci_ 3ple_por_armonizacion_legislativa.pdf $>$; <http://www.oit.org.pe/ipec/boletin/documentos/sensi_for_instir_por.pdf $>$; <http://www.oit.org.pe/ipec/documentos/ unicef_triplefrontera.pdf>; e <www.oimconosur.org/docs/pdf/340.pdf>.

13 A região de fronteira entre o Brasil e o Paraguai é invariavelmente apresentada pela mídia como uma região marcada pela violência e por diversas modalidades de atividades criminosas (tráfico de armas, drogas e seres humanos, exploração sexual comercial de crianças e adolescentes, presença de quadrilhas especializadas em roubo de carros e contrabando etc.). Um exemplo dessa representação é o livro $O$ país-bandido, escrito pelo jornalista Carlos Wagner (2003), a partir de uma série de reportagens publicadas no jornal Zero Hora, de Porto Alegre (RS).

Referências bibliográficas

ALBUQUERQUE, J. L. C. Fronteiras em movimento e identidades nacionais. A imi- 
gração brasileira no Paraguai. Fortaleza, 2005. Tese (Doutorado) - Programa de PósGraduação em Sociologia, Universidade Federal do Ceará.

ALVES, J. L. Brasiguaios: destino incerto. São Paulo: Global, 1990.

BATISTA, L. C. Brasiguaios na fronteira: caminhos e lutas pela liberdade. São Paulo, 1990. Dissertação (Mestrado) - Faculdade de Filosofia, Letras e Ciências Humanas, Universidade de São Paulo.

BOURDIEU, P. A miséria do mundo. Petrópolis: Vozes, 1997.

CARVAlHO, H.; ROMERO, A.; SPRANDEL, M. A. (Coord.) A exploração sexual comercial de crianças e adolescentes nas legislações da Argentina, Brasil e Paraguai: alternativas de harmonização para o Mercosul. Assunção: OIT/Programa IPEC Sudamérica, 2004.

CHAMPAGNE, P. A visão mediática. In: BOURDIEU, P. A miséria do mundo. Petrópolis: Vozes, 1997.

CORTÊZ, C. Brasiguaios: os refugiados desconhecidos. s. 1.. Brasil Agora, 1994?

COSTA, A. A. Cartografia da racionalidade moderna. In: MILOVIC, M.; SPRANDEL, M. (Org.) Sociedade e diferença. Brasília: Casa das Musas, 2005.

DIETRICH, W.; NOLL, V. O português do Brasil. Perspectivas da pesquisa atual. Madrid, Frankfurt: Iberoamericana, Vervuert, 2004.

FOGEL, R.; RIQUELME, M. Enclave sojero: merma de soberania y pobreza. Asunción: Ceri, 2005.

GUIMARÃES, A. O.; SPRANDEL, M. A. Coleção de boas práticas e lições aprendidas em prevenção e erradicação da exploração sexual comercial (ESC) de meninas, meninos e adolescentes: sensibilização e fortalecimento institucional. Asunción: OIT, 2005.

LAINO, D. Paraguai: fronteiras e penetração brasileira. São Paulo: Global, 1979.

MEAF - Ministério Extraordinário de Assuntos Fundiários. Diagnóstico fundiário/ Estado do MS. Coordenadoria Geral do MS-CR 16/ Departamento de Terras e Colonização de MS - Terrasul, 1984.

ORGANIZAÇÃO INTERNACIONAL para as Migrações (OIM). La trata de personas en el Paraguay, diagnóstico exploratório sobre el trafico y/o trata de personas con fines de explotación sexual. Asunción: OIM/Luna Nueva, 2005.

PALAU, T. Brasiguaios. In: Migrações Internacionais - Contribuições para políticas. Brasília: CNPD, 2001.

RABOSSI, F. Nas ruas de Ciudad del Este: vidas e vendas num mercado de fronteira. Rio de Janeiro, 2005. Tese (Doutorado) - PPGAS, Museu Nacional, 2005.

SANTA BÁRBARA, M. Des-caminhos brasileiros em terras paraguaias. Rio de Janeiro, 2005a. Dissertação (Mestrado) - Departamento de Geografia, Universidade Federal Fluminense.

. Brasiguaios: território e logos de identidades. In: NETO, H. P.; FERREIRA, A. P (Org.) Cruzando fronteiras disciplinares - Um panorama dos estudos migratórios. Rio de Janeiro: Revan, 2005b.

SANTOS, M. E. P. O cenário multilingüe/multidialetal de fronteira e o processo identitário de alunos brasiguaios no contexto escolar. Campinas, 2004. Tese (Doutorado) - Instituto de Estudos da Linguagem, Universidade Estadual de Campinas. 
SMITH, D. S. de C. S. Uma análise crítica da transferência de presos entre o Brasil e o Paraguai. Santa Maria, 2003. Dissertação (Mestrado em Integração Latino-Americana) - Universidade Federal de Santa Maria.

SOUCHARD, S. La formation d'un espace brésiguayen dans l'Est du Paraguay. Migrations pionnières brésiliennes et organisations socio-spatiales dans l'Oriente du Paraguay. Potiers, 2001. Thèse (Doctorat en Géographie) - Université de Poitiers.

Pionniers brésiliens au Paragnay. Paris: Kaethala, 2002.

SPRANDEL, M. A. Brasiguaios: conflito e identidade em fronteiras internacionais. Rio de Janeiro, 1992. Dissertação (Mestrado) - PPGAS, Museu Nacional.

. O Brasil olha o Paraguai: nossos pobres textos culturais sobre outro país latino-americano. Brasília, 1997. (Mimeogr.)

A terra é estrangeira, mas a da minha roça é igual. In: XXII ENCONTRO ANUAL DA ANPOCS. Caxambu, 1998.

Remando por este mundo de Deus - terras e territórios nas estratégias de reprodução camponesa. In: WOORTMANN, E. F. (Org.) Significados da terra. Brasília: Editora Universidade de Brasília, 2004.

SPRANDEL, M. A.; SCHELB, G. Z. Politicas públicas para o atendimento das demandas de cidadãos brasileiros no exterior - primeiras observações. Brasília, 2003. (Mimeogr.).

UNICEF - FUNDO DAS NAÇÕES UNIDAS PARA A INFÂNCIA - Oficina Regional do Unicef para a América Latina e o Caribe (Tacro). Situação das crianças e dos adolescentes na tríplice fronteira entre Argentina, Brasil e Paraguai: desafios e recomendações. Marcia Anita Sprandel (Coord.). Curitiba, Itaipu Binacional, 2005.

WAGNER, C. Brasiguaios: homens sem pátria. Petrópolis: Vozes, 1990.

Pais-bandido: crime tipo exportação. Porto Alegre: RBN, 2003.

RESUMO - O ARTIGO apresenta uma cartografia da situação social dos brasileiros e seus descendentes que vivem no Paraguai. Os distintos mapas (artigos, dissertações, teses e relatórios), com suas múltiplas perspectivas, permitem que se relativizem as narrativas midiáticas e a concepção da região como "lugar difícil". Ao discorrer sobre trabalhos de diversos autores, de distintas áreas acadêmicas, o artigo aponta para a mportância de cada um deles na construção de uma análise que traduza a pluralidade de pontos de vista coexistentes na região e que são, muitas vezes, inconciliáveis.

PALAVRAS-CHAVE: Emigração brasileira, Fronteira, Mídia, Paraguai, Brasiguaios.

ABSTRACT - THE ARTICLE presents a cartography of the social situation of the Brazilians and its descendants who live in Paraguay. The distinct maps (articles, these and reports) deconstruct the media's narratives and the conception of the region as a "difficult 
place". Works of diverse authors, of distinct academic areas, demonstrate the importance of each one of them in the construction of an analysis that translates the plurality of points of view.

KEYWORDS: Brazilian emigration, Frontier, Paraguay, Brasiguaios.

Marcia Anita Sprandel é bacharel em História (IFCS/UFRJ) e doutora em Antropologia social (UnB). Faz parte da Comissão de Relações Étnicas e Raciais da Associação Brasileira de Antropologia e é pesquisadora do Instituto Pensamento Social, de Brasília. @-marciasprandel@uol.com.br

Recebido em 12.6.2006 e aceito em 18.5.2006. 